\title{
A dynamic analysis of the demand for life insurance during the 2008 financial crisis: evidence from the panel Survey of Consumer Finances
}

\author{
Ning Wang ${ }^{1}(\mathbb{0}$
}

Received: 12 July 2021 / Accepted: 23 November 2021

(C) The Geneva Association 2021

\begin{abstract}
Prior research indicates a significant relation between life events and the demand for life insurance. This paper is the first study to relate the demand for life insurance to household portfolio holdings in a dynamic framework. The study examines changes in life insurance demand as a function of changes in household portfolio holdings and life events using panel data during the recent financial crisis. The results indicate that household portfolio holdings are more significant than life events in explaining life insurance ownership decisions, and suggest a complementary rather than a substitution relationship between the ownership of life insurance and the holdings of equity and bonds during recessions. The results also indicate that households with more financial assets allocated to bonds drop significantly more term life insurance coverage. Further implications for practitioners are discussed.
\end{abstract}

Keywords Life insurance $\cdot$ Household portfolio $\cdot$ Financial crisis $\cdot$ Household characteristics $\cdot$ Panel data

\section{Introduction}

Life insurance can mitigate financial losses and ensure that obligations can be paid for a household following the premature death of the wage earner. With high unemployment and bearish financial markets during an economic recession, households are likely to have a large amount of debt and a tight budget for various classes of

The author is grateful to participants at the 2020 World Risk and Insurance Economics Congress and 2020 Academy of Financial Services Annual Conference for their helpful suggestions and comments.

\section{Ning Wang}

ning.wang@ung.edu

1 Department of Economics and Finance, Mike Cottrell College of Business, University of North Georgia, 82 College Circle, Dahlonega, GA 30597, USA 
financial assets including equity, bonds and life insurance. In the event that households reduce or drop life insurance during recessionary times, households may sustain financial hardships that can result in significant economic consequences (Scott and Gilliam 2014). The effect of economic situations is also considered by insurers in their estimates of life insurance demand and business strategies. Given that previous research on the demand for life insurance has paid little attention to a recessionary time frame, it is important to explore the determinants of life insurance demand in a recession. This can potentially help lessen household financial hardship resulting from insufficient life insurance and help insurers to better understand the demand for life insurance during recessions. In the 2007-2009 financial crisis, stocks were among the financial assets with the sharpest declines in median value, while ownership of bonds and cash-value life insurance increased (Bricker et al. 2011). It is interesting to examine how household portfolio holdings can determine demand for life insurance during the 2008 financial crisis. This examination could provide insights to help financial planning practitioners and life insurance agents offer adaptive and comprehensive financial services for households that may experience changes in their portfolio holdings during recessions.

It is evident that the demand for life insurance is affected by the allocation of household financial assets. Fortune (1973) suggests that life insurance is a substitute for primary financial assets. An expectation of bullish (bearish) financial markets would stimulate (depress) household investment into primary securities and tend to depress (stimulate) the flow of funds into life insurance. Nevertheless, as noted for the real economy, the relationship between the demand for life insurance and the holdings of primary securities could be positive (Outreville 2013). The positive relationship could mean that better (worse) performance in the financial market is likely to be coincident with a growing (declining) economy and more (less) savings in a household. Headen and Lee (1974) note that it may well be that different financial asset alternatives are not competitive but rather complementary in the long run equilibrium. Lin and Grace (2007) find evidence of a positive association between life insurance holdings and risky financial assets. Zhu (2007) shows that term and whole life insurance are both positively related to stock purchase for individuals with power utility functions. The positive relationship could also be explained by financial market proximity and familiarity, which can boost both stock market participation and life insurance demand (Luciano et al. 2016). Besides financial assets, debt is also related to the demand for life insurance. Life insurance can be purchased to ensure that debts are paid on the debtor's/insured's death and the loan option of whole life insurance allows policyholders to borrow against cash value. Ferber and Lee (1980) note that debt rather than assets is the primary determinant of the demand for term life insurance. Lin and Grace (2007) point out that the effect of debt on life insurance demand could be ambiguous, while Hau (2000) finds limited evidence of a positive effect. Although the relation between the demand for life insurance and household portfolio holdings is not conclusive, it is clear that the consideration of household portfolio holdings in the analysis of the determinants of life insurance demand is necessary and feasible.

When considering household portfolio holdings, a dynamic analysis using panel data may provide the best basis for a deeper understanding of the determinants of 
life insurance demand. A rich strand of prior life insurance research employs crosssectional data to examine household demographic characteristics and economic status as influential factors in determining the demand for life insurance (see Mantis and Farmer 1968; Berekson 1972; Ferber and Lee 1980; Burnett and Palmer 1984; Miller 1985; Bernheim 1991; Lin and Grace 2007; Inkmann and Michaelides 2012; Luciano et al. 2016). It is noted by Hau (2000), Zietz (2003) and Outreville (2014) that these studies show mixed results on determinants including employment, family size, marital status, income, wealth and risk attitude. Liebenberg et al. (2012) use panel data from the 1983-1989 Survey of Consumer Finances (SCF), and find that the demand for life insurance is significantly associated with life events. Beyond this, there is little literature using dynamic analysis to explore the determinants of life insurance demand.

To the best of my knowledge, there have been no attempts in the literature to relate the demand for life insurance to household portfolio holdings in a dynamic framework. This paper is motivated by three aspects: a focus on a recessionary time frame, a better understanding of how household portfolio holdings can determine the demand for life insurance, and the employment of panel data for a dynamic analysis. The purpose of this paper is to examine changes in the demand for life insurance as a function of changes in household portfolio holdings and life events using panel data during the 2008 financial crisis. Changes in the demand for life insurance are examined using life insurance ownership decisions and coverage decisions. The results in this paper indicate that life events, including employment, retirement, family size and marital status, have a significant and dynamic effect on life insurance demand, consistent with prior literature. More importantly, the results indicate that household portfolio holdings are more significant than life events in determining life insurance ownership decisions during the financial crisis. A relevant study by Hau (2000) illustrates that financial portfolios appear to be more influential than household demographics in determining life insurance demand among retired people. It is implied in this paper that the ownership of life insurance is likely to be a complement to rather than a substitute for the holding of equity and bonds over the financial crisis. Specifically, the results reveal that households that increase the percentage of financial assets allocated to equity (bonds) are more likely to initiate or purchase more whole (both term and whole) life insurance, and these households are less likely to reduce or drop both term and whole life insurance. In addition, the relationship between life insurance ownership decisions and new debt application are found to be significant. The examination of life insurance coverage decisions indicates that households with an increase in asset allocation to bonds drop significantly more coverage of term life insurance.

The remainder of the article is organised as follows. The next section describes the causes and consequences of as well as solutions to the 2008 global financial crisis. The subsequent section reviews the relevant literature on the demand for life insurance. In the fourth section, the panel data and methodology used for the dynamic analysis of the demand for life insurance during the financial crisis are presented. The fifth section provides summary statistics of the data and the empirical results of the dynamic analysis. The final section concludes and further implications for practitioners and agents are presented. 


\section{The global financial crisis}

The recent global financial crisis started in December 2007 and ended in June $2009 .^{1}$ The financial crisis seriously impaired financial markets worldwide and distorted the broader economy (Melvin and Taylor 2009). It is important to address the causes and consequences of as well as solutions to this financial crisis in this paper, before examining the demand for life insurance during the period.

The financial crisis was initially caused by the subprime crisis due to the collapsing U.S. housing bubble. Allen and Carletti (2010) state that the housing bubble was attributed to loose monetary policy and global imbalances, and many other factors such as securitised subprime mortgages, weak regulatory structures and high leverage in financial institutions exacerbated the consequences of the crisis. The study of Sanders (2008) indicates that the fall in housing prices significantly contributed to the dramatic increase in seriously delinquent subprime mortgage rates. Whalen (2008) identifies three significant factors that caused the collapse of the subprime market, including public policies that enhanced the availability of affordable housing, omissions committed by regulators regarding over-the-counter derivatives, and the move to fair value accounting in reporting standards. Diamond and Rajan (2009) also identify two factors. One is the proliferation of complex financial instruments through repeated securitisation, and the other is financing with a capital structure heavy on short-term debts in banks. Gorton (2009) reveals the designs of a number of securities and derivatives related to subprime mortgages, including mortgagebacked securities (MBS) and collateralised debt obligations (CDOs), and explains how the chain of interlinked securities was sensitive to housing prices according to the rollover of mortgage loans through an implicit option and how the subprime risk was spread in an opaque way.

It is interesting to examine how problems in a rather small segment of the U.S. mortgage market (subprime crisis) could have such negative consequences for the entire financial market and the global economy. Bullard et al. (2009) explain that the issuance of complicated MBS and CDOs with highly opaque structures, inadequate risk management and high leverage played key roles in creating systemic risk through investor panic. Eichengreen et al. (2012) find that international banks' performance rose and fell together to a considerable extent even before the crisis, and common factors, associated with U.S. high-yield spreads, are identified to reflect the impact of the macroeconomy. They note that the importance of these common factors increased significantly during the crisis, with the entire global financial system infected. Following the U.S. subprime crisis, the European sovereign debt crisis began in 2008 with the collapse of Icelandic banks and peaked between 2010 and 2012, causing concerns about sovereign credit risk and redenomination risk in the fixed income securities market. Ureche-Rangau and Burietz (2013) show evidence of the significant link between the U.S. subprime crisis and the European sovereign debt crisis, embodied by government guarantees and capital inductions. Their study

\footnotetext{
1 See the National Bureau of Economic Research: https://www.nber.org/research/data/us-business-cycleexpansions-and-contractions.
} 
underlines the direct link between stock market returns evolution and sovereign risk premia. The spillover effects of the subprime crisis were also investigated by Wegener et al. (2019). They find that the European sovereign debt crisis was not sparked by the subprime crisis, while the subprime crisis triggered diverging European government bond yields in the course of the financial crisis.

One important consequence of this financial crisis is that the global financial system faced tremendous difficulties and central governments faced rising debts. Allen and Carletti (2010) suggest a number of reforms, including more intellectual banking regulation to correct market failures, more checks and balances in central banks, and limited government debt guarantees for banks. Bullard et al. (2009) suggest that establishing central exchanges for derivatives trading and creating an improved regime to increase supervision and resolve failures of large financial institutions can help mitigate systemic risk. To understand and remedy this financial crisis, the ideas of the heterodox schools of economic thought could also be of some interest. Dymski (2010) concludes that this financial crisis rendered an extensive roster of central bank interventions ineffectual, because banks are no longer as central in originating and bearing credit risks but rather distribute credit risks to minority and subprime borrowers. Ravier and Lewin (2012) explain that the Federal Reserve intentionally replaced the dot-com bubble with a housing bubble, with the money supply rapidly expanded and real interest rate reduced too low for too long. They also note that the Federal Reserve could have opted for open market operations rather than the selective rescue of some large companies that were too big to fail.

The financial crisis also had major implications for financial risk management in the financial industry. Stulz (2008) proposes that greater application of scenario analysis could allow institutions to do a better job of anticipating the likely consequences of low-probability outcomes with large losses, developing effective responses to them, and unfolding hidden risks. Rodriguez Gonzalez et al. (2021) investigate appropriate learning indicators for house prices to help implement forward-looking risk management approaches. They provide evidence that the National Association of Home Builders Market Index, an important sentiment indicator for economic activity in the U.S. real estate market, can help to robustly forecast house prices.

Besides the banking sector in the financial industry, the insurance sector was also affected by the financial crisis. The insurance sector is tied to many risks faced in the banking sector through its numerous holdings in banks and increased participation in financial instruments of capital markets (Baluch et al. 2011). The largest asset class held by U.S. life insurers is bonds; the second is mortgages, followed by stocks (Baranoff and Sager 2009a). Baranoff and Sager (2009b) report that life insurers had invested a significant proportion of their portfolios in MBS by the time of the financial crisis. They find that increases in MBS exposure were related to increases in asset risk and decreases in capital, indicating that life insurers failed to accommodate their capital structures to the ultimately greater risk of MBS. Baranoff and Sager (2011) found that, as the volatility of asset portfolios increased and sources of capital dried up during the financial crisis, the ability of insurers to maintain the pre-crisis relationship between asset and capital risks was impaired. They note that the impairment was greater in annuities and life insurance than in health lines since 
the segments that had relatively larger asset portfolios were hit harder by the crisis. Baluch et al. (2011) conclude that insurers that were well capitalised, did not dabble in credit-linked instruments, and did not aggressively use softer forms of capital had the best performance during the financial crisis.

The financial crisis pushed down government bond yields dramatically in the U.S., the U.K., and other countries. Basse et al. (2014) show structural change in 2009 in the time series of German long-term interest rates, implying that the process of interest rate determination was affected by the financial crisis. A low interest rate is a great threat to the life insurance industry, considering long-term interest rates serve as the valuation basis to determine premiums, policy reserves, profit-sharing and guaranteed rates of return (Holsboer 2000). Low interest rates can create severe financial problems and put great pressure on profits for life insurers, as the duration of liabilities is often longer than the duration of assets. Life insurers with a severe asset-liability-mismatch have to reinvest assets in bonds with lower yields than before and set aside additional policy reserves or raise premiums. Therefore, their existing business becomes more expensive to fund, and they tend to incur a loss at the point of sale for new business. This could result in high lapses or increased use of paid-up options on older policies (Holsboer 2000). In addition, if policyholders can obtain a higher return from other financial instruments, they are likely to drop life insurance with a saving component. To mitigate the low interest rate dilemma, equity-linked (unit-linked) products have experienced strong growth in the U.S., passing most of the investment risk on to the policyholder (Holsboer 2000). The threat of low interest rates to the life insurance industry is greater in some European counties such as Germany, where savings products with relatively high guaranteed rates and profit participation predominate in the life insurance market. The simulation by Berdin and Gründl (2015) shows that a prolonged period of low interest rates would dramatically affect the solvency status of life insurers, leading to a relatively high probability of default, especially for less capitalised insurers in Germany. They suggest that subsidising negative results on asset returns with other profit sources and reducing hidden reserves payout to policyholders can decrease the probability of insurer default. Eling and Holder (2013) provide a comparative analysis of different regulatory systems for the maximum technical interest rate of life insurance contracts in the U.S. and European countries. They suggest that the most appropriate solution is to combine expectations about the future yield development with today's backward-looking estimation procedure for a two component maximum technical interest rate, thereby not only maintaining an objective approach but also allowing for greater flexibility and more modern product design.

For households, the financial crisis led to rising unemployment, declines in the value of financial assets, and losses in wealth. Great uncertainty about the future price level of financial assets made it very difficult for households to make longterm financial decisions (Allen and Carletti 2010). The risk aversion of investors increased dramatically after the financial crisis, due to fears that a major financial crisis could adversely affect the price of less secure financial assets (Basse et al. 2014). Bricker et al. (2011) report higher precautionary savings and more riskaverse attitudes among U.S. households after the financial crisis. To some extent, households have learned from the financial crisis. O'Neill and Xiao (2012) compare 
financial practices before and after the crisis through an online financial self-assessment tool. They find that households obtained better scores for budgeting, spending and saving, and engaged frequently in commonly recommended financial practices, such as adequate insurance protection, after the financial crisis. In the case of life insurance, Swiss Re (2009) reports that sales of non-equity-linked savings products, including fixed annuities and traditional life savings, continued to increase in many countries, but failed to offset the severe declines in sales of equity-linked products during the financial crisis. Baluch et al. (2011) note that the cashing in of policies and the drop in the demand for new life insurance, particularly for mortgage-linked products and savings products, were severe, although claims payments did not increase during the financial crisis.

\section{Literature review of the demand for life insurance}

A rich body of empirical literature indicates that household demand for life insurance depends on corresponding demographic characteristics and economic status. These studies commonly apply cross-sectional data to examine the demand for life insurance within a static framework, given that the same households are rarely followed in household survey data. Hau (2000), Zietz (2003) and Outreville (2014) note that these studies show mixed evidence for household characteristics, including employment, family size, marital status, income, wealth and risk attitude, in determining the demand for life insurance. First, conflicting evidence exists for employment status. Duker (1969) finds that working-wife families spend substantially less on life insurance than those of other families with similar earnings, whereas Chen et al. (2001) find that women's positive cohort effects on life insurance demand are attributable to the increase in their labour participation rate. Mantis and Farmer (1968) show evidence of a negative influence of unemployment on the demand for life insurance. Luciano et al. (2016) demonstrate that life insurance demand is highly correlated with employment status. They find that women are less likely to be insured than are men, either because they do not contribute to household income, or because their roles are not monetised. Second, previous research shows mixed results on the effect of retirement on life insurance demand. Miller (1985) reports that retirees have less life insurance than active workers of the same age, which may be attributed to not having an employer to share in the cost or the lack of mandated retiree coverage. Inkmann and Michaelides (2012) show that life insurance participation is slightly increased during the early retirement period for retirees who hold stocks. Third, family size is found to be positively, negatively and not significantly related to life insurance demand. While Hammond et al. (1967) and Mantis and Farmer (1968) find that family size variables are negatively related to life insurance demand, there are many studies that find a higher demand for life insurance as family size increases (Berekson 1972; Ferber and Lee 1980; Burnett and Palmer 1984; Bernheim 1991; Luciano et al. 2016). Other relevant studies find no significance of or mixed results for family size (Duker 1969; Hau 2000). Fourth, mixed results exist for the effect of marital status on life insurance demand. Hammond et al. (1967) and Mantis and Farmer (1968) find that marriage has a negative effect on life insurance 
demand, whereas Burnett and Palmer (1984) and Bernheim (1991) find no significance. Berekson (1972) demonstrates that divorce has no significant effect on life insurance coverage. Lastly, although the level of risk aversion turns out to be positively correlated with life insurance demand in the theoretical literature (Schlesinger 1981; Zhu 2007; Wang 2019), the evidence is mixed, partially because measuring risk attitude in empirical research is complicated (Outreville 2014).

Due to the use of cross-sectional data coupled with the disparity in results in previous studies, Liebenberg et al. (2012) state that a dynamic analysis based on panel data may be better suited to explain life insurance holdings in terms of changes in household characteristics and to provide the basis for a better understanding of the determinants of life insurance demand. They use 1983-1989 SCF panel data to examine the determinants of life insurance demand in a dynamic setting. They present a significant relationship between life events, such as parenthood, a new job, and becoming widowed or unemployed, and life insurance demand. This data is also applied by Bertaut (1998) to examine the determinants of stock ownership decisions in a dynamic setting. The study demonstrates that households with lower risk aversion, higher education, and greater wealth who were non-stockholders in 1983 have an increased probability of entering stock markets by 1989. Analysis of the same panel data by Liebenberg et al. (2010) provides evidence of an increase in the demand for policy loans following recent expense or income shocks at the household level. This finding supports the emergency fund hypothesis that policyholders choose to surrender or borrow funds from a whole life insurance policy to gain access to emergency funds in the event of economic hardship, such as unusually large expenses and income shocks due to unemployment or reduced work hours (Outreville 1990; Liebenberg et al. 2012). Liebenberg et al. (2012) further find that unemployment is associated with the policy termination decision. Cole and Fier (2021) also provide new evidence to support the emergency fund hypothesis. Their study suggests that households tend to surrender their whole life insurance policies for longer-term financial needs, while temporary financial needs are more likely to be addressed with policy loans.

This paper extends the study of Liebenberg et al. (2012) in at least three ways. First, it uses more recent panel data. Second, this paper focuses on a time frame that includes a financial crisis. Third and importantly, besides life events, this paper examines household portfolio holdings as influential factors in determining changes in life insurance demand. Hau (2000) illustrates that financial portfolios appear to be more influential than household demographics in determining life insurance demand among retired people. He investigates the role of life insurance as a liquid financial asset on an insured's death, and finds that liquid conventional assets, including saving accounts, bonds and stocks, have negative effects on life insurance holdings. Headen and Lee (1974) present limited evidence that life insurance demand decreases with investment in stocks and bonds, but increases with savings accounts. Lin and Grace (2007) show evidence of how households change their portfolio at different life stages and how this relates to the demand for life insurance. They find a limited, negative relationship between life insurance holdings and bonds. Nevertheless, the sign of the relationship between life insurance demand and the holdings of stocks and bonds could also be positive, as noted for the real economy. Outreville 
(2013) states that a positive sign could indicate that better (worse) stock performance is more likely to coincide with a growing (declining) economy, rising (decreasing) household income and net worth, and more (less) savings in a household. The study by Headen and Lee (1974) reveals a positive relationship between stock index and life insurance holdings. They note that some asset holders may take securities market gains and adjust their portfolios to include more life insurance. Mayers and Smith (1983) state that when the insurance policy rewards are related to the returns of assets, insurance buying is not independent of other portfolio investment decisions. The study by Lin and Grace (2007) finds a positive relationship between life insurance holdings and individual retirement accounts, annuities and real estate. Luciano et al. (2016) confirm the role of financial market proximity, defined as an understanding of risky market values and payoffs, in explaining the willingness and the amount of hedging through life insurance. They present a positive and significant relation between stock ownership and life insurance demand, which signals that people who are more familiar with financial investments and who diversify are more willing to purchase life insurance.

Debt is also related to the demand for life insurance in a household. A household can purchase life insurance to ensure that obligations are paid on the debtor's/ insured's death. Whole life insurance can provide the loan option that allows policyholders to borrow against the policy's cash value (Smith 1982; Liebenberg et al. 2010). Ferber and Lee (1980) suggest that debts impact life insurance demand more than assets. They find that couples are less likely to buy life insurance if they have debt, as debts tend to swamp income in marriage. Their study also indicates that a larger amount of debt tends to motivate couples to acquire a larger amount of life insurance coverage to protect themselves. Hau (2000) demonstrates that life insurance death benefits may serve as immediate cash for paying debts and other death costs, and he finds limited evidence that debts have a positive effect on life insurance holdings. Lin and Grace (2007) point out that the relationship between life insurance and household debts could be ambiguous.

The theoretical literature has also addressed the relation between the demand for life insurance and household portfolio holdings. Yaari (1965) suggests that the consumer can separate the consumption decision from the bequest decision when insurance is available. Fortune (1973) notes that life insurance is a substitute for financial assets such as equities or other lower risk assets. Richard (1975) adds life insurance into an asset portfolio model, and derives the optimal demands for life insurance, consumption and stock purchase in a continuous-time framework. Zhu (2007) further shows that term and whole life insurance are both positively related with stock purchase for individuals with power utility functions.

\section{Data and models}

This paper aims to disclose the dynamic effect of household portfolio holdings and life events that are hypothesised to be associated with changes in life insurance demand during recessions, by examining household survey data from the SCF 
study. ${ }^{2}$ The study is normally a triennial cross-sectional survey of U.S. families, sponsored by the Federal Reserve Board in cooperation with the Department of the Treasury in the U.S. The data contains detailed information on household balance sheets, pensions, income, demographic characteristics and holdings of various financial assets including term and whole life insurance. There is no other study for the country that collects comparable information. The SCF data are widely used, from analysis at the Federal Reserve and other government agencies, to research work at the major economic research centres. ${ }^{3}$ SCF data have also been continuously used to study the demand for life insurance. ${ }^{4}$ While the SCF is not typically conducted on a panel basis, the survey has contained a panel element over two periods in history. Previously, respondents to the 1983 survey were re-interviewed in 1986 and 1989. More recently, in the 2007-2009 SCF panel study, about 89\% $(3,857)$ of eligible households in the 2007 SCF agreed to complete a panel interview in 2009 and were included. ${ }^{5}$ This panel data allows the identification of changes in life insurance demand, household portfolio holdings and household characteristics (or life events) for the same household since 2007, which is well suited to studying influential factors that affect the demand for life insurance in a dynamic setting. This panel data also allows a unique analysis of how households were affected by the 2008 financial crisis.

In this paper, changes in the demand for life insurance are examined in terms of life insurance ownership decisions and coverage decisions (see Liebenberg et al. 2012). Life insurance ownership decisions include initiating, increasing, decreasing and dropping term or whole life insurance. There are four categories of households identified from the panel data that experienced changes in life insurance ownership from 2007 to 2009: (1) new or increased term life insurance, (2) new or increased whole life insurance, (3) decreased or dropped term life insurance, and (4) decreased or dropped whole life insurance. Four categories of life insurance coverage decisions are identified: (1) the amount of newly purchased or increased term life insurance coverage, (2) the amount of newly purchased or increased whole life insurance coverage, ${ }^{6}(3)$ the amount of decreased or dropped term life insurance coverage, and (4) the amount of decreased or dropped whole life insurance coverage. Changes in household portfolio holdings examined in this paper include: (1) whether to increase the percentage of financial assets allocated to equity, (2) whether to increase the percentage of financial assets allocated to bonds, and (3) whether to apply for new

\footnotetext{
2 As in Liebenberg et al. (2012), SCF data is preferred in this paper to other sources of household panel data on life insurance holdings, such as the University of Michigan Health and Retirement Study (HRS) and Consumer Expenditure Surveys (CEX). The HRS data focuses on households over the age of 50 only, and the CEX data does not distinguish life insurance from other personal insurance.

3 See the official website of the SCF study: https://www.federalreserve.gov/econres/aboutscf.htm.

4 See Hau (2000), Lin and Grace (2007), Liebenberg et al. (2012), Scott and Gilliam (2014) and Cole and Fier (2021).

5 Consistent with Lin and Grace (2007) and Liebenberg et al. (2012), the first implicate, or record, of each SCF household is analysed in this paper.

${ }^{6}$ Whole life insurance coverage in this paper refers to the net amount of whole life insurance at risk, which is defined as the difference between the face value and cash value of whole life insurance policies.
} 
debts. As in Liebenberg et al. (2012), life events are based on changes in household characteristics that are subject to mixed results in previous literature, such as becoming unemployed, getting a new job, retiring, additions or decreases in the number of children, becoming divorced, becoming separated and being more risk averse. These explanatory variables are captured according to the comparison of household portfolio holdings and household characteristics between the initial interview in 2007 and the re-interview in 2009.

As in Bertaut (1998) and Liebenberg et al. (2012), four models with probit regressions are applied to explore influential factors in determining household life insurance ownership decisions, as described in Eqs. (1) to (4).

$$
\begin{aligned}
\text { NewIncrTerm }_{i}= & \alpha+\beta_{1} \text { MoreEquity }_{i}+\beta_{2} \text { MoreBond }_{i}+\beta_{3} \text { NewDebt }_{i}+\beta_{4} \text { NewJob }_{i} \\
& +\beta_{5} \text { NewKids }_{i}+\beta_{6} \text { NewMarried }_{i}+\beta_{7} \text { RiskAverse }_{i}+\beta_{8} \text { IncomePct }_{i} \\
& +\beta_{9} \text { NetWorthPct }_{i}+\beta_{10} \text { DropDecrWhole }_{i}+\text { Control Variables } \varepsilon_{i},
\end{aligned}
$$

NewIncrWhole $_{i}=\alpha+\beta_{1}$ MoreEquity $_{i}+\beta_{2}$ MoreBond $_{i}+\beta_{3}$ NewDebt $_{i}+\beta_{4}$ NewJob $_{i}$

$$
\begin{aligned}
& +\beta_{5} \text { NewKids }_{i}+\beta_{6} \text { NewMarried }_{i}+\beta_{7} \text { RiskAverse }_{i}+\beta_{8} \text { IncomePct }_{i} \\
& +\beta_{9} \text { NetWorthPct }_{i}+\beta_{1} \text { DropDecrTerm }_{i}+\text { Control Variables }+\varepsilon_{i},
\end{aligned}
$$

DropDecrTerm $_{i}=\alpha+\beta_{1}$ MoreEquity $_{i}+\beta_{2}$ MoreBond $_{i}+\beta_{3}$ NewDebt $_{i}+\beta_{4}$ NewUnemployed $_{i}$

$$
\begin{aligned}
& +\beta_{5} \text { NewRetired }_{i}+\beta_{6} \text { LossKids }_{i}+\beta_{7} \text { NewWidowed }_{i}+\beta_{8} \text { NewSeparated }_{i} \\
& +\beta_{9} \text { NewDivorced }_{i}+\beta_{10} \text { RiskAverse }_{i}+\beta_{11} \text { IncomePct }_{i}+\beta_{12} \text { NetWorthPct }_{i} \\
& +\beta_{13} \text { NewIncrWhole }_{i}+\text { Control Variables }+\varepsilon_{i},
\end{aligned}
$$

$$
\begin{aligned}
\text { DropDecrWhole }_{i}= & \alpha+\beta_{1} \text { MoreEquity }_{i}+\beta_{2} \text { MoreBond }_{i}+\beta_{3} \text { NewDebt }_{i} \\
& +\beta_{4} \text { NewUnemployed }_{i}+\beta_{5} \text { NewRetired }_{i}+\beta_{6} \text { LossKids }_{i} \\
& +\beta_{7} \text { NewWidowed }_{i}+\beta_{8} \text { NewSeparated }_{i}+\beta_{9} \text { NewDivorced }_{i} \\
& +\beta_{10} \text { RiskAverse }_{i}+\beta_{11} \text { IncomePct }_{i}+\beta_{12} \text { NetWorthPct }_{i} \\
& +\beta_{13} \text { NewIncrTerm }_{i}+\text { Control Variables }+\varepsilon_{i},
\end{aligned}
$$

Then, to explore the determinants of life insurance coverage decisions conditional on the ownership decisions, a truncated regression is applied (see Cragg 1971; Liebenberg et al. 2012). Four truncated regression models are described in Eqs. (5) and (8) to examine the four life insurance coverage decision categories.

$$
\begin{aligned}
\text { LnNewIncrTerm }_{i}= & \alpha+\beta_{1} \text { MoreEquity }_{i}+\beta_{2} \text { MoreBond }_{i}+\beta_{3} \text { NewDebt }_{i} \\
& +\beta_{4} \text { NewJob }_{i}+\beta_{5} \text { NewKids }_{i}+\beta_{6} \text { NewMarried }_{i} \\
& +\beta_{7} \text { RiskAverse }_{i}+\beta_{8} \text { IncomePct }_{i}+\beta_{9} \text { NetWorthPct }_{i} \\
& +\beta_{10} \text { LnDropDecrWhole }_{i}+\text { Control Variables } \\
& +\varepsilon_{i}, \text { where NewIncrTerm }_{i}=1,
\end{aligned}
$$


LnNewIncrWhole $_{i}=\alpha+\beta_{1}$ MoreEquity $_{i}+\beta_{2}$ MoreBond $_{i}+\beta_{3}$ NewDebt $_{i}$

$+\beta_{4}$ NewJob $_{i}+\beta_{5}$ NewKids $_{i}+\beta_{6}$ NewMarried $_{i}$

$+\beta_{7}$ RiskAverse $_{i}+\beta_{8}$ IncomePct $_{i}+\beta_{9}$ NetWorthPct $_{i}$

$+\beta_{10}$ LnDropDecrTerm $_{i}+$ Control Variables

$+\varepsilon_{i}$, where NewIncrWhole , $_{i}=1$,

LnDropDecrTerm $_{i}=\alpha+\beta_{1}$ MoreEquity $_{i}+\beta_{2}$ MoreBond $_{i}+\beta_{3}$ NewDebt $_{i}$

$+\beta_{4}$ NewUnemployed $_{i}+\beta_{5}$ NewRetired $_{i}+\beta_{6}$ LossKids $_{i}$

$+\beta_{7}$ NewWidowed $_{i}+\beta_{8}$ NewSeparated $_{i}+\beta_{9}$ NewDivorced $_{i}$

$+\beta_{10}$ RiskAverse $_{i}+\beta_{11}$ IncomePct $_{i}+\beta_{12}$ NetWorthPct $_{i}$

$+\beta_{13}$ LnNewIncrWhole $_{i}+$ Control Variables

$+\varepsilon_{i}$, where DropDecrTerm ${ }_{i}=1$,

LnDropDecrWhole $_{i}=\alpha+\beta_{1}$ MoreEquity $_{i}+\beta_{2}$ MoreBond $_{i}+\beta_{3}$ NewDebt $_{i}$

$+\beta_{4}$ NewUnemployed $_{i}+\beta_{5}$ NewRetired $_{i}+\beta_{6}$ LossKids $_{i}$

$+\beta_{7}$ NewWidowed $_{i}+\beta_{8}$ NewSeparated $_{i}+\beta_{9}$ NewDivorced $_{i}$

$+\beta_{10}$ RiskAverse $_{i}+\beta_{11}$ IncomePct $_{i}+\beta_{12}$ NetWorthPct $_{i}$

$+\beta_{13}$ LnNewIncrTerm $_{i}+$ Control Variables

$+\varepsilon_{i}$, where DropDecrWhole ${ }_{i}=1$,

NewIncrTerm (NewIncrWhole) is an indicator variable equal to 1 for households that initiated a term (whole) life insurance policy or increased term (whole) life insurance coverage since 2007, and 0 otherwise. DropDecrTerm (DropDecrWhole) is an indicator variable equal to 1 for households that dropped a term (whole) life insurance policy or decreased term (whole) life insurance coverage since 2007, and 0 otherwise. LnNewIncrTerm (LnNewIncrWhole) is the natural log of the amount of newly purchased or increased term (whole) life insurance coverage. LnDropDecrTerm (LnDropDecrWhole) is the natural log of the amount of decreased or dropped term (whole) life insurance coverage.

The three explanatory variables for household portfolio holdings are defined as follows. MoreEquity and MoreBond are indicator variables equal to 1 for households that increased the percentage of financial assets allocated to equity or bonds in 2009 compared with the initial interview in 2007, and 0 otherwise. Equity here refers to all financial assets invested in stock, including directly-held stock, stock mutual funds, IRAs/Keoghs invested in stock and other managed assets with equity interest, such as annuities and trusts. NewDebt is an indicator variable equal to 1 for households with new debt application since 2007, and 0 otherwise. Similar ideas are applied to define explanatory variables regarding life events. In Eqs. (1), (2), (5) and (6), NewJob is equal to 1 for households with either spouse finding a new job since 2007, and 0 otherwise. NewKids is equal to the number of new children in a household since 2007, and 0 otherwise. NewMarried is equal to 1 for households that became married since 2007, and 0 otherwise. In Eqs. (3), (4), (7) and 
(8), NewUnemployed and NewRetired are equal to 1 for households in which either spouse became unemployed or retired since 2007, and 0 otherwise. LossKids is equal to the decrease in the number of children in a household since $2007,{ }^{7}$ and 0 otherwise. NewWidowed, NewSeparated and NewDivorced are equal to 1 for households that became widowed, divorced or separated since 2007, respectively, and 0 otherwise. In all equations, RiskAverse is an indicator variable equal to 1 for households with more risk averse attitudes in 2009 than in 2007, and 0 otherwise. IncomePct and NetWorthPct are calculated as the percentage change in household income or net worth from 2007 to 2009. These three variables are developed to explore the impact of changes in household economic status on the demand for life insurance.

Control variables in each equation represent household characteristics and economic situations that commonly appeared in prior research. ${ }^{8}$ Work is equal to 1 if either spouse was employed in 2007, and 0 otherwise. LnIncome is the natural log of household income in 2007, and LnIncome2 is equal to the square of LnIncome. LnNetWorth is the natural log of household net worth in 2007. Married is equal to 1 for married households in 2007, and 0 otherwise. Risk is equal to 1 if households preferred no financial risk in 2007, and 0 otherwise. EquityShare is the percentage of financial assets invested in equity markets in 2007. Age3549 (Age5064; Age65_) is equal to 1 if the age of the respondent was between 35 and 49 (between 50 and 64; 65 or older) in 2007, and 0 otherwise. Kid is the number of children in a household in 2007. White is equal to 1 for white households, and 0 otherwise. College is equal to 1 if either spouse had a college education in 2007, and 0 otherwise. Homeowner is equal to 1 if households owned the primary residence in 2007, and 0 otherwise.

Considering the endogeneity problems that may arise due to the inclusion of substitution effects in these eight regression models, they are tested through the Wald exogeneity test. The test suggests that NewIncrTerm is endogenous in Eq. (4), but fails to reject the exogeneity in all other equations. As a result, Eqs. (1) to (3) are estimated using probit regression and Eqs. (5) to (8) are estimated using truncated regression, while Eq. (4) is estimated using two-stage-least-squares (2SLS). According to these regressions, variables of household portfolio holdings and life events that have a significant and dynamic impact on life insurance ownership decisions and coverage decisions are identified.

\footnotetext{
7 The SCF survey asks respondents to list the children who live with the respondent with an assumption that children under the age of 18 are financially dependent on the respondent. Therefore, a decrease in the number of children for a household can be attributed to the decease of children under the age of 18 or the case that adult children no longer live with the respondent.

${ }^{8}$ To check for robustness, all the regressions in this paper were run again with all the control variables using the 2009 data instead of the 2007 data. The results show no significant difference from the main results of this paper, which indicates that the analysis and the results of this paper are completely robust. A note that the control variable of 'White' (or the race of the household) is constant across these two years.
} 
Table 1 Summary statistics $(n=3857)$

\begin{tabular}{lccc}
\hline Variables & Median & Mean & SD \\
\hline Life insurance ownership decisions & & \\
NewIncrTerm & 0 & 0.28 & 0.45 \\
NewIncrWhole & 0 & 0.18 & 0.39 \\
DropDecrTerm & 0 & 0.29 & 0.45 \\
DropDecrWhole & 0 & 0.19 & 0.39
\end{tabular}

Life insurance coverage decisions

LnNewIncrTerm
LnNewIncrWhole
LnDropDecrTerm
LnDropDecrWhole

3.22

5.26

2.01

4.38

3.30

5.32

Household portfolio holdings

MoreEquity
MoreBond
NewDebt
Life events
NewJob
NewKids
NewMarried
NewUnemployed
NewRetired
LossKids
NewWidowed
NewSeparated
NewDivorced

2.09

4.47

0.33

0.47

0.09

0.28

0

1

0.74

0.44

Life events

Other explanatory variables

\begin{tabular}{llrr} 
RiskAverse & 0 & 0.27 & 0.44 \\
IncomePct & -5.43 & 1.19 & 57.89 \\
NetWorthPct & -19.80 & -1.52 & 87.89 \\
Control variables & & & \\
Work & 1 & 0.76 & 0.43 \\
LnIncome & 11.25 & 11.57 & 2.01 \\
LnIncome2 & 126.50 & 137.82 & 46.24 \\
LnNetWorth & 12.66 & 12.12 & 4.36 \\
Married & 1 & 0.69 & 0.46 \\
Risk & 0 & 0.30 & 0.46 \\
EquityShare & 23.80 & 30.66 & 31.00 \\
Age3549 & 0 & 0.30 & 0.46 \\
Age5064 & 0 & 0.34 & 0.47 \\
Age65_- & 0 & 0.21 & 0.41 \\
Kid & 0 & 0.88 & 1.20 \\
White & 1 & 0.77 & 0.42 \\
College & 1 & 0.57 & 0.50 \\
Homeowner & 1 & 0.76 & 0.43 \\
\hline
\end{tabular}

$\begin{array}{lll}0 & 0.04 & 0.19\end{array}$


Table 2 Results for new life insurance ownership

\begin{tabular}{|c|c|c|c|c|}
\hline \multirow{2}{*}{$\begin{array}{l}\text { Dependent variable } \\
\text { Independent variables }\end{array}$} & \multicolumn{2}{|l|}{ NewIncrTerm } & \multicolumn{2}{|l|}{ NewIncrWhole } \\
\hline & Coefficient estimate & SE & Coefficient estimate & SE \\
\hline MoreEquity & -0.110800 & $0.049200 * *$ & 0.108000 & $0.054700 * *$ \\
\hline MoreBond & 0.179400 & $0.091100 * *$ & 0.238500 & $0.092400 * * *$ \\
\hline NewDebt & -0.086400 & 0.058900 & -0.106200 & $0.062900 *$ \\
\hline NewJob & -0.064600 & 0.056700 & 0.139200 & $0.067300^{* *}$ \\
\hline NewKids & -0.066300 & 0.056000 & -0.014300 & 0.066000 \\
\hline NewMarried & -0.079000 & 0.122300 & -0.212800 & 0.139500 \\
\hline RiskAverse & 0.055300 & 0.054500 & 0.096400 & 0.059900 \\
\hline IncomePct & -0.001490 & $0.000428 * * *$ & -0.001400 & $0.000469 * * *$ \\
\hline NetWorthPct & -0.000520 & $0.000265^{*}$ & -0.000800 & $0.000308^{* * * *}$ \\
\hline DropDecrWhole & -0.436700 & $0.056100 * * *$ & & \\
\hline DropDecrTerm & & & -0.379200 & $0.052200^{* * *}$ \\
\hline Work & -0.104100 & 0.066000 & 0.015600 & 0.070400 \\
\hline LnIncome & -0.155000 & $0.052400^{* * *}$ & -0.006130 & 0.047900 \\
\hline LnIncome2 & 0.007050 & $0.002330 * * *$ & -0.001510 & 0.002220 \\
\hline LnNetWorth & -0.005030 & 0.009150 & -0.044600 & $0.011800^{* * *}$ \\
\hline Married & -0.139200 & $0.055900 * *$ & -0.034900 & 0.061600 \\
\hline Risk & 0.081100 & 0.064100 & 0.085400 & 0.071100 \\
\hline EquityShare & -0.002530 & $0.000873 * * *$ & 0.002420 & $0.000968 * *$ \\
\hline Age 3549 & -0.044200 & 0.072300 & -0.088800 & 0.089900 \\
\hline Age 5064 & 0.198000 & $0.079400 * *$ & -0.134100 & 0.095000 \\
\hline Age65_ & 0.481400 & $0.100800^{* * *}$ & -0.291600 & $0.112300 * * *$ \\
\hline Kid & 0.008100 & 0.020900 & 0.011600 & 0.023900 \\
\hline White & -0.070100 & 0.057700 & 0.065700 & 0.064800 \\
\hline College & -0.011400 & 0.053600 & -0.044600 & 0.059700 \\
\hline Homeowner & -0.116700 & 0.071000 & -0.111200 & 0.081800 \\
\hline Intercept & 1.899500 & $0.337700 * * *$ & 1.961400 & $0.325600 * * *$ \\
\hline Observations & 3857 & & 3857 & \\
\hline Wald exogeneity test & 0.408 & & 0.225 & \\
\hline
\end{tabular}

\section{Results}

\section{Summary statistics and data comparison}

The summary statistics of the variables in the regressions are listed in Table 1. It shows that approximately 28\% (18\%) of households that were re-interviewed in 2009 had initiated or increased their holdings of term (whole) life insurance since 2007. About 29\% (19\%) of households that owned term (whole) life insurance in 2007 had dropped or decreased their term (whole) life insurance in 2009. In addition, approximately 33\% of households that were re-interviewed in 2009 had increased asset allocation to equity, $9 \%$ had increased asset allocation to bonds, and $74 \%$ had applied for 
Table 3 Results for dropped life insurance ownership

\begin{tabular}{|c|c|c|c|c|}
\hline \multirow{2}{*}{$\begin{array}{l}\text { Dependent variable } \\
\text { Independent variables }\end{array}$} & \multicolumn{2}{|l|}{ DropDecrTerm } & \multicolumn{2}{|l|}{ DropDecrWhole } \\
\hline & Coefficient estimate & SE & Coefficient estimate & SE \\
\hline MoreEquity & -0.110200 & $0.049200 * *$ & -0.239200 & $0.116100^{* *}$ \\
\hline MoreBond & -0.054200 & 0.086500 & 0.259300 & 0.183300 \\
\hline NewDebt & -0.196700 & $0.058100 * * *$ & -0.458000 & $0.114700 * * *$ \\
\hline NewUnemployed & -0.010900 & 0.104100 & 0.774700 & $0.346500 * *$ \\
\hline NewRetired & -0.259700 & $0.089600 * * *$ & 0.143000 & 0.157300 \\
\hline LossKids & -0.118000 & $0.051700 * *$ & 0.059800 & 0.082600 \\
\hline NewWidowed & -0.137700 & 0.190800 & -0.375700 & 0.269100 \\
\hline NewSeparated & -0.110900 & 0.194800 & 0.851500 & $0.460500 *$ \\
\hline NewDivorced & 0.030700 & 0.116200 & 0.341300 & 0.270800 \\
\hline RiskAverse & -0.166700 & $0.054100 * * *$ & 0.121300 & 0.083900 \\
\hline IncomePct & 0.001560 & $0.000445 * * *$ & -0.002060 & 0.001370 \\
\hline NetWorthPct & 0.000669 & $0.000274 * *$ & -0.000930 & $0.000551^{*}$ \\
\hline NewIncrWhole & -0.395800 & $0.055500 * * *$ & & \\
\hline NewIncrTerm & & & 5.827000 & $3.032900 *$ \\
\hline Work & -0.246400 & $0.065000 * * *$ & -0.088600 & 0.120100 \\
\hline LnIncome & -0.011400 & 0.044500 & -0.225200 & $0.130000^{*}$ \\
\hline LnIncome2 & 0.001600 & 0.002070 & 0.009980 & 0.006080 \\
\hline LnNetWorth & 0.012000 & 0.009140 & -0.047200 & $0.012800 * * *$ \\
\hline Married & -0.165500 & $0.055400 * * *$ & -0.490900 & $0.178200^{* * *}$ \\
\hline Risk & -0.132300 & $0.063900 * *$ & 0.504400 & $0.135900 * * *$ \\
\hline EquityShare & -0.001270 & 0.000870 & -0.000120 & 0.002180 \\
\hline Age3549 & -0.110200 & 0.074500 & -0.078600 & 0.096900 \\
\hline Age 5064 & -0.262100 & $0.079400 * * *$ & 0.074300 & 0.204100 \\
\hline Age65_ & -0.042500 & 0.099400 & 0.461700 & 0.451200 \\
\hline Kid & 0.009100 & 0.022700 & -0.055600 & $0.026600 * *$ \\
\hline White & 0.039500 & 0.057200 & -0.191800 & $0.103300^{*}$ \\
\hline College & -0.113300 & $0.053400 * *$ & -0.089700 & 0.061300 \\
\hline Homeowner & -0.094900 & 0.070800 & -0.362700 & $0.145600 * * *$ \\
\hline Intercept & 1.307700 & $0.290600 * * *$ & 2.107200 & $0.331300 * * *$ \\
\hline Observations & 3857 & & 3857 & \\
\hline Wald exogeneitytTest & 0.352 & & $0.065^{*}$ & \\
\hline
\end{tabular}

new debts since 2007. The results also show that $27 \%$ of households became more risk averse, $9 \%$ had new children, with the number of new children being 0.11 on average, $12 \%$ had a lower number of children, with the number of children decreasing by 0.15 on average, $3 \%$ married, and $1 \%$ separated since 2007 .

The 2007-2009 panel data set is more recent than the panel data set of 1983-1989 examined by Liebenberg et al. (2012). Due to the economic situation, the analysis of this more recent panel data set shows a much lower percentage of households that initiated or increased life insurance than in 1983-1989 (28\% versus $41 \%$ for term life 
insurance; $18 \%$ versus $29 \%$ for whole life insurance). Additionally, the households in the recent data increased their life insurance coverage by a lower amount than those in the previous data. The results are not surprising considering the adverse effect of the financial crisis on the economy and financial markets. The percentage of households that dropped or decreased whole life insurance in the recent data is much lower than that in the previous data (19\% versus 34\%), and the life insurance coverage among these households decreased by a lower amount than those in the previous data. This might be because primary security markets are less attractive during recessions and more funds are retained within life insurance markets. Regarding household employment status, the comparison shows a much higher unemployment rate $(5 \%$ versus $2 \%$ ), a much lower retirement rate (6\% versus $16 \%$ ), a much lower working rate $(76 \%$ versus $90 \%)$, and a higher percentage of households with job changes ( $22 \%$ versus $18 \%$ ) during the financial crisis. Regarding household economic status, households in the recent data had a much lower income growth rate (1.2\% versus $12.5 \%$ ), a much lower net worth growth rate ( $-1.5 \%$ versus $45.4 \%)$, and a lower homeownership rate $(76 \%$ versus $80 \%)$ than those in the previous data. Households in the recent data also had a higher divorce rate (4\% versus $3 \%$ ), a much lower widow rate ( $1 \%$ versus $5 \%)$, and less children ( 0.88 versus 1.05$)$ than those in the previous data. As in the previous data, the vast majorty of households were employed, married and homeowners in 2007-2009.

\section{Life insurance ownership decisions}

Tables 2 and 3 show the influential factors, in terms of household portfolio holdings and life events, that can significantly determine life insurance ownership decisions, while holding other determinants of life insurance demand constant. The results indicate that household portfolio holdings are more significant than life events in explaining life insurance ownership decisions during the financial crisis.

Table 2 indicates that households that increased the percentage of financial assets allocated to equity since 2007 (MoreEquity) were more likely to initiate or purchase more whole life insurance (NewIncrWhole) in 2009 compared to other households. This may be attributed to portfolio rebalancing and adjustment among these households during recessions. The positive relation could be due to the fact that financial market proximity boosts both stock market participation and the demand for life insurance (see Luciano et al. 2016). Moreover, these households are less likely to terminate or reduce whole life insurance (DropDecrWhole) than are other households during the financial crisis, as shown in Table 3. This might be related to an increase in risk aversion after the financial crisis, as indicated in the literature (Bricker et al. 2011; Basse et al. 2014). During economic downturn, risky assets are less attractive, so households would like to retain some funds in life insurance rather than flow funds into risky assets. The relation between equity holdings and whole life insurance ownership decisions illustrated in both tables suggests that the ownership of whole life insurance is complementary to the holding of equity during recessions. For term life insurance, Table 2 indicates that households that increased 
their asset allocation to equity are less likely to initiate or purchase more term life insurance (NewIncrTerm). This implies that more funds flowing into equity markets tends to depress the decision to purchase new or more term life insurance during recessions. On the other hand, Table 3 indicates that these households are less likely to drop or decrease term life insurance (DropDecrTerm) than are other households, which provides evidence of a complementary relationship between the holding of equity and the ownership of term life insurance during the financial crisis. In all, the results suggest that life insurance is not a substitute for, but rather a complement to, equity holdings during recessions (see Zhu 2007; Lin and Grace 2007; Luciano et al. 2016).

For bond holdings, Table 2 provides evidence that an increase in the percentage of financial assets allocated to bonds (MoreBond) can significantly stimulate the decisions to initiate or increase both term and whole life insurance during the financial crisis. In a healthy economy, higher household income and wealth can stimulate both bond holdings and insurance holdings. During recessions, it is not irrational for a household to invest more funds in lower risk assets to keep liquidity, and at the same time, to purchase new or more life insurance to have the household protected. This might also be related to increased risk aversion after the financial crisis. The positive relation between life insurance ownership decisions and bond holdings also implies that financial market proximity can boost both financial market participation and the demand for life insurance (Luciano et al. 2016). The results in these two tables suggest that life insurance is likely to act as a complementary asset rather than a substitute for the holdings of equity and bonds during recessions. This is consistent with the note by Headen and Lee (1974) that different financial asset alternatives may well be more complementary than competitive in the long-run equilibrium, depending on the economy and interest rate.

The relationship between life insurance ownership decisions and new debt application (NewDebt) is also found to be significant. On one hand, Table 2 shows that households with new debt applications are less likely to purchase new or more whole life insurance than are other households, which might be attributed to a tighter budget with potential new debts (Ferber and Lee 1980). On the other hand, and more significantly, these households are less likely to reduce or drop both term and whole life insurance than are other households during the financial crisis, as shown in Table 3. This indicates that life insurance is held by a household to help ensure that obligations are paid on the insured's death (Ferber and Lee 1980; Hau 2000; Lin and Grace 2007).

The results also provide evidence that life events can determine life insurance ownership decisions. Table 2 shows that households that had a new job since 2007 (NewJob) were more likely to initiate or increase whole life insurance than were other households in 2009. This provides new evidence to support the positive relationship between new employment and the demand for whole life insurance found by Liebenberg et al. (2012). Table 3 further indicates that the decision to drop or decrease whole life insurance is significantly and positively associated with becoming unemployed. This is consistent with the finding by Liebenberg et al. (2012) that unemployed households were more likely than other households to surrender their whole life insurance, and provides new evidence in support of the emergency 
Table 4 Results for new life insurance coverage

\begin{tabular}{|c|c|c|c|c|}
\hline \multirow{2}{*}{$\begin{array}{l}\text { Dependent variable } \\
\text { Independent variables }\end{array}$} & \multicolumn{2}{|l|}{ LnNewIncrTerm } & \multicolumn{2}{|l|}{ LnNewIncrWhole } \\
\hline & Coefficient estimate & SE & Coefficient estimate & SE \\
\hline MoreEquity & 0.126962 & 0.090727 & 0.067660 & 0.161000 \\
\hline MoreBond & 0.011055 & 0.183166 & -0.074002 & 0.262067 \\
\hline NewDebt & 0.217449 & $0.118989 *$ & -0.034426 & 0.184331 \\
\hline NewJob & 0.173454 & $0.103741^{*}$ & 0.244686 & 0.211514 \\
\hline NewKids & 0.099452 & 0.095240 & 0.451562 & $0.216937 * *$ \\
\hline NewMarried & -0.122574 & 0.216032 & 0.110628 & 0.407026 \\
\hline RiskAverse & -0.314159 & $0.100252^{* * *}$ & -0.093037 & 0.174152 \\
\hline IncomePct & 0.002828 & $0.000869^{* * *}$ & 0.004151 & $0.001294 * * *$ \\
\hline NetWorthPct & 0.000258 & 0.000491 & 0.001944 & $0.000940 * *$ \\
\hline LnDropDecrWhole & 0.050135 & $0.008375^{* * *}$ & & \\
\hline LnDropDecrTerm & & & 0.017761 & 0.012044 \\
\hline Work & 0.499831 & $0.130716^{* * *}$ & 0.062869 & 0.204180 \\
\hline LnIncome & -0.083397 & 0.107953 & -0.624813 & $0.128500 * * *$ \\
\hline LnIncome2 & 0.045640 & $0.017448 * * *$ & 0.061230 & $0.035322 *$ \\
\hline LnNetWorth & 0.021090 & $0.004722 * * *$ & 0.052641 & $0.006293 * * *$ \\
\hline Married & 0.650272 & $0.107767 * * *$ & 0.361410 & $0.184732 *$ \\
\hline Risk & -0.404883 & $0.124146^{* * *}$ & -0.054249 & 0.208821 \\
\hline EquityShare & 0.000583 & 0.001575 & -0.001462 & 0.002884 \\
\hline Age 3549 & 0.008107 & 0.130205 & -0.616417 & $0.298820 * *$ \\
\hline Age 5064 & -0.467372 & $0.142780 * * *$ & -1.046893 & $0.317499 * * *$ \\
\hline Age65_ & -0.887478 & $0.194502^{* * * *}$ & -1.539718 & $0.361488^{* * *}$ \\
\hline Kid & 0.057346 & 0.040017 & 0.097773 & 0.070895 \\
\hline White & -0.030455 & 0.109673 & -0.373623 & $0.195630^{*}$ \\
\hline College & 0.116779 & 0.097822 & 0.082370 & 0.181314 \\
\hline Homeowner & -0.117968 & 0.132474 & 0.019710 & 0.243990 \\
\hline Intercept & 8.068814 & $0.707574 * * *$ & 10.642411 & $0.902916 * * *$ \\
\hline Observations & 1078 & & 700 & \\
\hline Wald exogeneity test & 0.964 & & 0.801 & \\
\hline
\end{tabular}

fund hypothesis (see Outreville 1990; Liebenberg et al. 2010; Cole and Fier 2021). Table 3 provides evidence that the decision to drop or decrease term life insurance is negatively associated with new retirement (NewRetired). A relevant study by Inkmann and Michaelides (2012) shows that life insurance participation during the early retirement period is roughly constant among non-stockholders and slightly increased for stockholders. Table 3 also indicates that households in which the number of children decreased more (LossKids) are less likely to drop or decrease term life insurance during the financial crisis. A relevant study by Liebenberg et al. (2012) finds that new parents are more likely to initiate or increase term life insurance.

Table 2 indicates that households that experience relatively high growth in income and net worth (IncomePct and NetWorthPct) have a lower probability of 
Table 5 Results for dropped life insurance coverage

\begin{tabular}{|c|c|c|c|c|}
\hline \multirow{2}{*}{$\begin{array}{l}\text { Dependent variable } \\
\text { Independent variables }\end{array}$} & \multicolumn{2}{|l|}{ LnDropDecrTerm } & \multicolumn{2}{|l|}{ LnDropDecrWhole } \\
\hline & Coefficient estimate & SE & Coefficient estimate & SE \\
\hline MoreEquity & 0.030441 & 0.093280 & -0.195468 & 0.156275 \\
\hline MoreBond & 0.341310 & $0.166460 * *$ & 0.145681 & 0.234674 \\
\hline NewDebt & 0.184630 & 0.120520 & 0.045665 & 0.190184 \\
\hline NewUnemployed & -0.003774 & 0.199120 & 0.146253 & 0.439481 \\
\hline NewRetired & 0.341080 & $0.157940 * *$ & 0.107136 & 0.254867 \\
\hline LossKids & 0.201660 & $0.093486^{* *}$ & 0.066676 & 0.162423 \\
\hline NewWidowed & 0.426300 & 0.366240 & -0.478672 & 0.567055 \\
\hline NewSeparated & 0.054997 & 0.344870 & -0.931684 & 0.685199 \\
\hline NewDivorced & 0.195240 & 0.221890 & -1.132275 & $0.384215^{* * * *}$ \\
\hline RiskAverse & -0.056623 & 0.100410 & 0.505517 & $0.163232 * * *$ \\
\hline IncomePct & 0.001408 & 0.000882 & 0.000508 & 0.001426 \\
\hline NetWorthPct & 0.000015 & 0.000557 & -0.000949 & 0.001049 \\
\hline LnNewIncrWhole & 0.029097 & $0.008607 * * *$ & & \\
\hline LnNewIncrTerm & & & 0.059198 & $0.012077 * * *$ \\
\hline Work & 0.135810 & 0.135370 & 0.426255 & $0.200264 * *$ \\
\hline LnIncome & -0.356580 & $0.084704 * * *$ & -0.451805 & $0.127385 * * *$ \\
\hline LnIncome2 & 0.076420 & $0.018516 * * *$ & 0.034611 & $0.005936^{* * *}$ \\
\hline LnNetWorth & 0.031748 & $0.003953 * * *$ & 0.158730 & $0.040270 * * *$ \\
\hline Married & 0.383140 & $0.111580 * * *$ & 0.473693 & $0.200116^{* *}$ \\
\hline Risk & -0.279900 & $0.121530 * *$ & 0.317080 & 0.219849 \\
\hline EquityShare & 0.000453 & 0.001663 & -0.001502 & 0.003003 \\
\hline Age3549 & -0.529790 & $0.154700 * * *$ & -0.326470 & 0.297740 \\
\hline Age 5064 & -0.641710 & $0.161440 * * *$ & -0.832334 & $0.302909 * * *$ \\
\hline Age65_ & -1.390700 & $0.201030 * * *$ & -0.955854 & $0.351310 * * *$ \\
\hline Kid & 0.092316 & $0.044989 * *$ & 0.049020 & 0.078377 \\
\hline White & -0.121400 & 0.107710 & -0.520763 & $0.209468 * *$ \\
\hline College & 0.437730 & $0.103290 * * *$ & 0.103205 & 0.172700 \\
\hline Homeowner & 0.133460 & 0.142400 & 0.125489 & 0.278388 \\
\hline Intercept & 9.873800 & $0.571000^{* * * *}$ & 8.977854 & $0.900546 * * *$ \\
\hline Observations & 1103 & & 724 & \\
\hline Wald exogeneity test & 0.219 & & 0.373 & \\
\hline
\end{tabular}

initiating or increasing term and whole life insurance during the financial crisis, and Table 3 further indicates that these households have a higher probability of dropping or decreasing term life insurance. This implies that improvements in financial well-being might not be able to stimulate new demand for life insurance, and that increased household income and net worth may not primarily flow into life insurance markets during recessions. This also implies that households with greater income and net worth can afford to self-insure. This is different from the findings of Liebenberg et al. (2012) but consistent with the study by Lewis (1989) that life 
insurance is negatively associated with net worth. In addition, Table 3 shows a significant and negative relationship between risk-averse attitudes (RiskAverse) and the decision to drop or decrease term life insurance in the financial crisis, which is due to greater awareness of the ability of life insurance to protect households from financial losses during recessions. This is consistent with the theoretical literature (see Schlesinger 1981; Zhu 2007; Wang 2019).

\section{Life insurance coverage decisions}

Tables 4 and 5 report influential factors in terms of portfolio holdings and life events that can significantly determine life insurance coverage decisions, while holding other demand determinants constant. They indicate that household portfolio holdings have little impact on life insurance coverage decisions during recessions. Table 4 indicates that the amount of new term life insurance coverage is related to new debt application. Table 5 indicates that households with an increase in asset allocation to bonds drop significantly more term life insurance coverage, which could be attributed to the substitution effect between lower risk assets and life insurance holdings (see Fortune 1973; Hau 2000).

Regarding life events, Table 5 shows that the amount of reduced term life insurance coverage is significantly related to retirement and the number of children, consistent with prior research (Miller 1985; Ferber and Lee 1980; Burnett and Palmer 1984; Bernheim 1991; Luciano et al. 2016). The results indicate that although households in which the number of children decreased to a greater extent or those that retired are less likely to drop or decrease term life insurance (see Table 3), they will reduce their term life insurance coverage more significantly than other households if they are determined to do so. For whole life insurance, Table 4 indicates that households that have a higher number of new children (NewKids) purchase significantly more whole life insurance coverage than other households, while Liebenberg et al. (2012) indicate that new parents purchase significantly more term life insurance coverage than others. Table 5 indicates that reduced whole life insurance coverage is significantly smaller in newly divorced households (NewDivorced) than in other households.

Regarding household economic status, Table 4 indicates that households that experience relatively high growth in income and net worth (only income) purchased a significantly larger amount of whole (term) life insurance coverage during the financial crisis. This implies that improvements in financial well-being can help increase life insurance coverage for existing policyholders.

\section{Conclusions and discussions}

Previous research on the demand for life insurance has focused on examining life insurance holdings as a function of household demographic characteristics and economic status. The limited amount of literature using panel data coupled with the lack of attention paid to a recessionary time frame in previous research provided the 
motivation for this paper. A comparison of the results presented in this paper with those from prior research illustrates important insights that are obtained by analysing the dynamic effect of determinants of life insurance demand and by considering the financial crisis.

This paper expands the literature through a dynamic analysis of the demand for life insurance during recessions, by identifying the variables of household portfolio holdings and life events that significantly and dynamically affected life insurance ownership and coverage decisions during the recent financial crisis. The results indicate that household portfolio holdings are more significant than life events in explaining life insurance ownership decisions during recessions. They also suggest a complementary rather than a substitution relationship between life insurance ownership and holding of equity and bonds during recessions. The results also reveal a significant association between the decision to drop or decrease life insurance and new debt application. Household portfolio holdings are also shown to have little impact on life insurance coverage decisions during recessions. The results provide evidence of the substitution effect between term life insurance holdings and lower risk assets, as well as new evidence in support of the emergency fund hypothesis. They further indicate that life events, such as employment, retirement, changes in family size, and marital status, have a significant and dynamic effect on the demand for life insurance.

An important implication of the determinants of life insurance demand identified in this paper is that they are useful predictors of changes in life insurance demand at the household level during recessions. These findings are fundamental for insurers, considering that insurers account for the effect of economic situations in their estimates of life insurance demand and product design and marketing strategies. Further, they can also help financial planning practitioners and life insurance agents to illustrate dynamic life insurance needs, develop adaptive and comprehensive financial plans for various households, and improve their services to households that may experience changes in portfolio holdings and life events during recessions.

There are further implications for insurers, practitioners, agents and social policymakers. First, this paper suggests that ways to expand household life insurance demand during recessions may include fostering the education and participation of stock and bond markets, improving employment, and increasing birth rates. Second, while it is evident that improving household financial well-being might not stimulate new demand for life insurance during recessions, it may help to increase life insurance coverage for existing policyholders. Third, the analysis of households that dropped or reduced life insurance in this paper can shed light on how to lessen financial hardship from insufficient life insurance. For example, it is suggested that policyholders with an increased percentage of financial assets allocated to bonds tend to reduce a significantly larger amount of term life insurance coverage than other households, and that newly unemployed households are more likely to reduce or drop whole life insurance than others. It is also suggested that retired households or those in which the number of children decreased are less likely to drop or decrease term life insurance, but they will do so more significantly if they are determined to drop or decrease term life insurance. Focusing on these particular groups during 
recessions can be of tremendous value to social policymakers who work on mitigating household financial hardship due to insufficient life insurance coverage.

\section{Appendix 1}

Survey questions pertaining to the demand for life insurance in the codebook of the 2007-2009 Survey of Consumer Finances panel data set are listed as follows. For more information, see https://www.federalreserve.gov/econres/files/codebk2009p. txt.

1. Ownership of term life insurance

\section{X4002: QUESTION TEXT SAME AS 2009 VERSION}

P4002: The two major types of life insurance are term and cash-value policies. Term policies pay a benefit if the insured person dies, but otherwise have no value. They are often provided through an employer or union, but may also be bought by individuals. Cash-value policies also pay a death benefit, but differ in that they build up a value as premiums are paid. Are any of your (family's) policies term insurance?

2. Coverage of term life insurance

X4003: QUESTION TEXT SAME AS 2009 VERSION

P4003: What is the current face value of all the term life policies that you (and your family living here) have? (THE FACE VALUE OF A POLICY IS WHAT THE POLICY WOULD PAY IN THE EVENT OF DEATH)

3. Ownership of whole life insurance

X4004: QUESTION TEXT SAME AS 2009 VERSION

P4004: Do you have any policies that build up a cash value or that you can borrow on? These are sometimes called "whole life", "straight life", or "universal life" policies.

4. Coverage of whole life insurance

X4005: QUESTION TEXT SAME AS 2009 VERSION

P4005: What is the current face value of all of the policies that build up a cash value? (THE FACE VALUE OF A POLICY IS WHAT THE POLICY WOULD PAY IN THE EVENT OF DEATH.)

X4006: QUESTION TEXT SAME AS 2009 VERSION

P4006: If you cancelled these policies now, how much would you receive from the insurance company for the payments you have made up to now? That is, what is the current "cash value" of the policies? 


\section{Appendix 2}

The variables of household portfolio holdings are based on the macro codebook of the 2007-2009 Survey of Consumer Finances panel data set, listed as follows. For more information, see https://www.federalreserve.gov/econres/files/fedstables. macro.txt.

1. Equity

Equity $=$

Stocks $+0.5 * \mathrm{NMMF}+\& \mathrm{~V} 091003 *((\& \mathrm{~V} 091004=1)+(\& \mathrm{~V} 091004=3 \mid \& \mathrm{~V} 091004=30) *($ $\operatorname{MAX}(0, \& \mathrm{~V} 091005) / 10000))+\mathrm{ANNUIT} *((\& \mathrm{~V} 6581=1)+(\& \mathrm{~V} 6581=3 \mid \& \mathrm{~V} 6581=30) *($ $\operatorname{MAX}(0, \& \mathrm{~V} 6582) / 10000))+$ TRUSTS $((\& \mathrm{~V} 6591=1)+(\& \mathrm{~V} 6591=3 \mid \& \mathrm{~V} 6591=30) *(\mathrm{M}$ $\mathrm{AX}(0, \& \mathrm{~V} 6592) / 10000))+\mathrm{PENEQ}+\mathrm{MAX}(0, \& \mathrm{~V} 091127) *((\& \mathrm{~V} 091128=1)+(\& \mathrm{~V} 09112$ $8=3 \mid \& V 091128=30) *(\operatorname{MAX}(0, \& \mathrm{~V} 091129) / 10000))+\& \mathrm{~V} 091008 *((\& \mathrm{~V} 091016=1) *($ $\operatorname{MAX}(0, \& \mathrm{~V} 091017) / 10000))$;

2. Bonds

$\mathrm{BOND}=\operatorname{MAX}(0, \& \mathrm{~V} 091021)$

3. Financial assets

$\mathrm{FIN}=$

LIQ+CDS+NMMF+STOCKS+BOND+RETQLIQ+SAVBND+CASHLI+OTHMA+ OTHFIN;

4. New debt application

APPLIED $=(\&$ V09201=1 $)$

\section{References}

Allen, F., and E. Carletti. 2010. An overview of the crisis: Causes, consequences, and solutions. International Review of Finance 10: 1-26.

Baluch, F., S. Mutenga, and C. Parson. 2011. Insurance, systemic risk and the financial crisis. The Geneva Papers on Risk and Insurance-Issues and Practice 36: 126-163.

Baranoff, E.G., and T.W. Sager. 2009a. Do life insurers' asset allocation strategies influence performance within the enterprise risk framework? The Geneva Papers on Risk and Insurance-Issues and Practice 34: 242-259.

Baranoff, E.G., and T.W. Sager. 2009b. The impact of mortgage-backed securities on capital requirements of life insurers in the financial crisis of 2007-2008. The Geneva Papers on Risk and Insurance-Issues and Practice 34: 100-118.

Baranoff, E.G., and T.W. Sager. 2011. The interplay between insurers' financial and asset risks during the crisis of 2007-2009. Geneva Papers on Risk and Insurance 36: 348-379.

Basse, T., M. Friedrich, A. Kleffner, and J.M.G. von der Schulenburg. 2014. Are interest rates too low? Empirical evidence and implications for German life insurers. Zeitschrift Für Die Gesamte Versicherungswissenschaft 103: 31-43. 
Berdin, E., and H. Gründl. 2015. The effects of a low interest rate environment on life insurers. The Geneva Papers on Risk and Insurance - Issues and Practice 40: 385-415.

Berekson, L.L. 1972. Birth order, anxiety, affiliation and the purchase of life insurance. Journal of Risk and Insurance 39 (1): 93-108.

Bernheim, B.D. 1991. How strong are bequest motives? Evidence based on estimates of the demand for life insurance and annuities. Journal of Political Economy 99: 899-927.

Bertaut, C.C. 1998. Stockholding behavior of US households: Evidence from the 1983-1989 survey of consumer finances. Review of Economics and Statistics 80: 263-275.

Bricker, J., B. Bucks, A.B. Kennickell, T. Mach, and K.B. Moore. 2011. Surveying the aftermath of the storm: changes in family finances from 2007 to 2009 . Working Paper.

Bullard, J., C.J. Neely, and D.C. Wheelock. 2009. Systemic risk and the financial crisis: A primer. Federal Reserve Bank of St. Louis Review 91: 403-418.

Burnett, J.J., and B.A. Palmer. 1984. Examining life insurance ownership through demographic and psychographic characteristics. Journal of Risk and Insurance 51 (3): 453-467.

Chen, R., K.A. Wong, and H.C. Lee. 2001. Age, period, and cohort effects on life insurance purchases in the US. Journal of Risk and Insurance 68 (2): 303-327.

Cole, C.R., and S.G. Fier. 2021. An examination of life insurance policy surrender and loan activity. Journal of Risk and Insurance 88: 483-516.

Cragg, J.G. 1971. Some statistical models for limited dependent variables with application to the demand for durable goods. Econometrica: Journal of the Econometric Society 39: 829-844.

Diamond, D.W., and R.G. Rajan. 2009. The credit crisis: Conjectures about causes and remedies. American Economic Review 99: 606-610.

Duker, J.M. 1969. Expenditures for life insurance among working-wife families. Journal of Risk and Insurance 36 (5): 525-533.

Dymski, G.A. 2010. Why the subprime crisis is different: A Minskyian approach. Cambridge Journal of Economics 34: 239-255.

Eichengreen, B., A. Mody, M. Nedeljkovic, and L. Sarno. 2012. How the subprime crisis went global: Evidence from bank credit default swap spreads. Journal of International Money and Finance 31: $1299-1318$.

Eling, M., and S. Holder. 2013. Maximum technical interest rates in life insurance in Europe and the United States: An overview and comparison. The Geneva Papers on Risk and Insurance-Issues and Practice 38: 354-375.

Ferber, R., and L.C. Lee. 1980. Acquisition and accumulation of life insurance in early married life. Journal of Risk and Insurance 47 (4): 713-734.

Fortune, P. 1973. A theory of optimal life insurance: Development and test. The Journal of Finance 28: 587-600.

Gorton, G. 2009. The subprime panic. European Financial Management 15: 10-46.

Hammond, J.D., D.B. Houston, and E.R. Melander. 1967. Determinants of household life insurance premium expenditures: An empirical investigation. Journal of Risk and Insurance 34 (3): 397-408.

Hau, A. 2000. Liquidity, estate liquidation, charitable motives, and life insurance demand by retired singles. Journal of Risk and Insurance 67 (1): 123-141.

Headen, R.S., and J.F. Lee. 1974. Life insurance demand and household portfolio behavior. Journal of Risk and Insurance 41 (4): 685-698.

Holsboer, J.H. 2000. The impact of low interest rates on insurers. The Geneva Papers on Risk and Insurance-Issues and Practice 25: 38-58.

Inkmann, J., and A. Michaelides. 2012. Can the life insurance market provide evidence for a bequest motive? Journal of Risk and Insurance 79: 671-695.

Lewis, F.D. 1989. Dependents and the demand for life insurance. The American Economic Review 79: 452-467.

Liebenberg, A.P., J.M. Carson, and R.E. Dumm. 2012. A dynamic analysis of the demand for life insurance. Journal of Risk and Insurance 79: 619-644.

Liebenberg, A.P., J.M. Carson, and R.E. Hoyt. 2010. The demand for life insurance policy loans. Journal of Risk and Insurance 77: 651-666.

Lin, Y., and M.F. Grace. 2007. Household life cycle protection: Life insurance holdings, financial vulnerability, and portfolio implications. Journal of Risk and Insurance 74: 141-173.

Luciano, E., J.F. Outreville, and M. Rossi. 2016. Life insurance ownership by Italian households: A gender-based differences analysis. The Geneva Papers on Risk and Insurance-Issues and Practice 41: $468-490$. 
Mantis, G., and R.N. Farmer. 1968. Demand for life insurance. Journal of Risk and Insurance 35 (2): 247-256.

Mayers, D., and C.W. Smith Jr. 1983. The interdependence of individual portfolio holdings and the demand for insurance. Journal of Political Economy 91: 304-311.

Melvin, M., and M.P. Taylor. 2009. The global financial crisis: Causes, threats and opportunities. Introduction and overview. Journal of International Money and Finance 28: 1243-1245.

Miller, M.A. 1985. Age-related reductions in workers' life insurance. Monthly Labor Review 108: 29.

O'Neill, B., and J.J. Xiao. 2012. Financial behaviors before and after the financial crisis: Evidence from an online survey. Journal of Financial Counseling and Planning 23: 33-46.

Outreville, J.F. 1990. Whole-life insurance lapse rates and the emergency fund hypothesis. Insurance: Mathematics and Economics 9: 249-255.

Outreville, J.F. 2013. The relationship between insurance and economic development: 85 empirical papers for a review of the literature. Risk Management and Insurance Review 16: 71-122.

Outreville, J.F. 2014. Risk aversion, risk behavior, and demand for insurance: A survey. Journal of Insurance Issues 37 (2): 158-186.

Ravier, A.O., and P. Lewin. 2012. The subprime crisis. Quarterly Journal of Austrian Economics 15: 45-74.

Richard, S.F. 1975. Optimal consumption, portfolio and life insurance rules for an uncertain lived individual in a continuous time model. Journal of Financial Economics 2: 187-203.

Rodriguez Gonzalez, M., T. Basse, D. Saft, and F. Kunze. 2021. Leading indicators for US house prices: New evidence and implications for EU financial risk managers. European Financial Management. https://doi.org/10.1111/eufm.12325.

Sanders, A. 2008. The subprime crisis and its role in the financial crisis. Journal of Housing Economics 17: 254-261.

Schlesinger, H. 1981. The optimal level of deductibility in insurance contracts. Journal of Risk and Insurance 48: $465-481$.

Scott, J.K., and J. Gilliam. 2014. Boomers' life insurance adequacy pre-\& post the 2008 financial crisis. Financial Services Review 23: 287-304.

Smith, M.L. 1982. The life insurance policy as an options package. Journal of Risk and Insurance 49: 583-601.

Stulz, R.M. 2008. Risk management failures: What are they and when do they happen? Journal of Applied Corporate Finance 20: 39-48.

Swiss Re. 2009. World insurance in 2008. Sigma No. 3.

Ureche-Rangau, L., and A. Burietz. 2013. One crisis, two crises... the subprime crisis and the European sovereign debt problems. Economic Modelling 35: 35-44.

Wang, N. 2019. The demand for life insurance in a heterogeneous-agent life cycle economy with joint decisions. The Geneva Risk and Insurance Review 44: 176-206.

Wegener, C., R. Kruse, and T. Basse. 2019. The walking debt crisis. Journal of Economic Behavior and Organization 157: 382-402.

Whalen, R.C. 2008. The subprime crisis-cause, effect and consequences. Journal of Affordable Housing and Community Development Law 17 (3): 219-235.

Yaari, M.E. 1965. Uncertain lifetime, life insurance, and the theory of the consumer. The Review of Economic Studies 32: 137-150.

Zhu, Y. 2007. One-period model of individual consumption, life insurance, and investment decisions. Journal of Risk and Insurance 74: 613-636.

Zietz, E.N. 2003. An examination of the demand for life insurance. Risk Management and Insurance Review 6: 159-191.

Publisher's Note Springer Nature remains neutral with regard to jurisdictional claims in published maps and institutional affiliations. 


\section{About the author}

Ning Wang is an Associate Professor of Finance in the Mike Cottrell College of Business at the University of North Georgia in the U. S. She received a Ph.D. degree in Risk Management and Insurance from Georgia State University, and previously served as an Assistant Professor at Valdosta State University. Her research interests include insurance economics, dynamic modelling, life insurance and financial planning. 